\title{
Synthesis of 2-chloro- $N, N, N$-trialkylethanaminium salts and related hydroxy-analogues as analytical standards for monitoring potential chemical warfare agent precursors
}

\author{
Jakub Stýskala, ${ }^{a}$ Petr Cankař, ${ }^{a}{ }^{*}$ Michal Maloň, ${ }^{b}$ Iveta Fryšová, ${ }^{a}$ Petr Bednářr, and \\ Karel Lemr ${ }^{c}$ \\ ${ }^{a}$ Department of Organic Chemistry, Palacky University, Tr. Svobody 8, 77146 Olomouc, \\ Czech Republic \\ ${ }^{b}$ Laboratory of Growth Regulators, Institute of Experimental Botany, AS CR and Palacky \\ University, Slechtitelu 11, 78371 Olomouc, Czech Republic \\ ${ }^{c}$ Department of Analytical Chemistry, Palacky University, Tr. Svobody 8, 77146 Olomouc, \\ Czech Republic \\ E-mail: cankar@orgchem.upol.cz
}

\begin{abstract}
A set of choline related derivatives of 2-chloro- $N, N, N$-trialkylethanaminium salts $N$-substituted with some simple alkyl groups has been prepared and characterized by standard methods. Two methodologies based on alkylation were developed. One utilized the direct alkylation of 2chloro- $N, N$-dialkylethanamines to afford the desired aminium salts. Whenever this method failed a three-step methodology starting with the alkylation of the 2-(dialkylamino)ethanols was used. All these derivatives can be used as analytical standards for monitoring potential chemical warfare agent precursors mainly by the HPLC-MS methods.
\end{abstract}

Keywords: 2-Chloro- $N, N, N$-trialkylethanaminium salts, alkylation of amines, 2-(dialkylamino)ethanols, chemical warfare agent precursors

\section{Introduction}

The modern history of wars is stigmatized by the use of poisonous compounds for targeted liquidation of humans. The menace of military or terrorist attack employing toxic preparations persists till today and it is ubiquitous in the modern globalized world. Therefore, fast and reliable control of the movement of chemical weapons as well as potentially exploitable compounds or their precursors is a crucial and, unfortunately, a complex task. For that reason sophisticated analytical approaches allowing detection of very low concentration of the target compound in a complex matrix (e.g. environmental or clinical samples) have to be adopted. However, to provide 
true and decisive results, comparison with a well defined standard sample proving unambiguously the identity and/or allowing precise determination is often indispensable.

Among other controlled precursors of chemical warfare agents (CWA) 2-chloro- $N, N$ dialkylethanamines, their corresponding hydroxy and mercapto derivatives with short alkyl chains are listed in the "Convention on the Prohibition of the Development, Production, Stockpiling and Use of Chemical Weapons and on their Destruction" (OPCW). ${ }^{1}$ These compounds have been widely studied from the standpoint of their synthesis (including tagged compounds) ${ }^{2}$ as well as analytical procedures. ${ }^{3,4}$ Compared to $N, N$-dialkylaminoethyls, the related N-quaternary compounds are not officially considered as precursors of CWA (i.e. listed in the above mentioned document of OPCW). However, there are indications that such derivatives can be utilized for the production of potent CWA. First, an analogy with 3Quinuclidine derivatives can be considered. Quaternarization of 3-Quinuclidine (precursor of 3Quinuclidinol benzilate, a strong nerve poison causing disorientation and hallucinations) increases its capability to inhibit choline uptake in cholinergic neurons (regulation of acetylcholine synthesis) ${ }^{5}$. Second, during the investigation of so-called Tammelin esters ${ }^{6,7}$ it was found that related choline esters (i.e. quaternary $N, N, N$-trimethylethanaminiums, e.g. 2$\{[$ fluoro(methoxy)phosphoryl]oxy $\}-N, N, N$-trimethylethanaminium) are more toxic than isopropyl methylfluorophosphonate (Sarin) despite their low stability due to hydrolysis. ${ }^{8-10}$

The chemical analogy of quaternary derivatives with choline is a cogent argument for the investigation of 2-chloro- $N, N, N$-trialkylethanaminium salts and related hydroxy derivatives from the viewpoint of their synthesis, analysis and biological activity. 2-chloro- $N, N, N-$ trimethylethanaminium salt (chlorocholine, chlormequat) is a generally known plant growth regulator. However, preparations based on this compound are classified as highly toxic irritants. Triethylcholine was found to be a false-transmitter generating a choline analogue causing a similar depression of biological activity. ${ }^{11}$ Several articles have been devoted to the pharmacological investigation of unsymmetrical choline analogues (e.g. monoethylcholine and diethylcholine). The results obtained suggest that these compounds significantly influence the functioning of cholinergic neurons and that the effect depends on the substitution. ${ }^{12}$ This paper, a continuation of our previous research on CWA precursors, ${ }^{2-4,13,14}$ is focused on the synthesis of choline analogues including some possible combinations of $N$-substitutions with methyl, ethyl, propyl and isopropyl chains and related 2-chloro- $N, N, N$-trialkylethanaminium salts for the use as analytical standards.

\section{Results and Discussion}

The choice of the methodology to prepare choline analogues related to 2-chloro- $N, N, N$ trialkylethanaminium salts appeared to be simple at first glance. It was decided to use commercially available derivatives of 2-chloro- $N, N$-dialkylethanamine, convert them to the corresponding free base $\mathbf{1}$ and immediately alkylate this with the appropriate iodoalkane. 


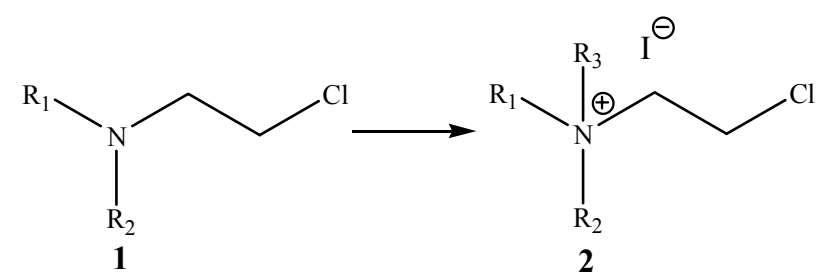
a) $\mathrm{R}_{1}=\mathrm{Me}, \mathrm{R}_{2}=\mathrm{Me}$
e) $\mathrm{R}_{1}=\mathrm{Me}, \mathrm{R}_{2}=\mathrm{Me}, \mathrm{R}_{3}=\mathrm{Et}$
h) $R_{1}=\mathrm{Me}, \mathrm{R}_{2}=\mathrm{Et}, \mathrm{R}_{3}=\mathrm{Et}$
b) $R_{1}=E t, R_{2}=E t$
f) $R_{1}=\mathrm{Me}, \mathrm{R}_{2}=\mathrm{Me}, \mathrm{R}_{3}=\mathrm{n}-\mathrm{Pr}$
i) $R_{1}=E t, R_{2}=E t, R_{3}=n-P r$
c) $R_{1}=E t, R_{2}=n-P r$
g) $R_{1}=\mathrm{Me}, \mathrm{R}_{2}=\mathrm{Et}, \mathrm{R}_{3}=\mathrm{n}-\mathrm{Pr}$
j) $R_{1}=M e, R_{2}=n-P r, R_{3}=n-P r$
d) $\mathrm{R}_{1}=\mathrm{n}-\mathrm{Pr}, \mathrm{R}_{2}=\mathrm{n}-\mathrm{Pr}$

Scheme 1. Method A.

In this way (Scheme 1 - Method A) the corresponding commercially available hydrochlorides were treated with an aqueous solution of sodium hydroxide to obtain amines $1 \mathbf{1 a - d}{ }^{13,15}$ which were subsequently alkylated with iodoalkane in a mixture of acetone and diethyl ether at ambient temperature for 72 hours. The respective aminium iodide salts $\mathbf{2}$, resulted. The yields were not exceptionally high (44-56\%) since our focus was on preparing samples of the highest possible purity. While the derivatives $2 \mathbf{g}, \mathbf{2} \mathbf{i}$ and $\mathbf{2 j}$ have not been described previously, the derivatives $\mathbf{2 e},{ }^{16} \mathbf{2} \mathbf{f}^{17}$ and $\mathbf{2} \mathbf{h}^{18}$ are known. Since these references provide less exact or different preparation protocols and characteristic data of particular derivatives are missing or inadequately described, we report these data coherently and more exactly.

Method A has also limitations. While the alkylation reaction of $\mathrm{N}$-(2-chloroethyl), $\mathrm{N}$ propylpropan-1-amine 1d with iodomethane takes place at ambient temperature, in the case of iodoethane or 1-iodopropane no reaction occurs, most likely due to steric hindrance. If the temperature was raised the formation of a single product was observed in an excellent yield indicated by molecular peaks $\mathrm{m} / \mathrm{z}=128$ and 171 in the MS spectrum (electrospray ionization). This suggested a possible competitive cyclization reaction furnishing the 6-membered ring compound 3 or 3 -membered ring product 7 (Scheme 2 - The competitive cyclization). The reaction was also carried out under identical conditions without presence of iodoalkanes, with only the starting $N$-(2-chloroethyl)- $N$-propylpropan-1-amine 1d. The formation of the piperazinium derivative $\mathbf{3}$ proceeds remarkable slowly and the yield of the reaction decreased to $5 \%$ (dichloride anion).

Since it was not possible to elucidate the structure of the product arised by the competitive cyclization from its MS spectrum, we carefully analyzed ${ }^{1} \mathrm{H}$ and ${ }^{13} \mathrm{C}$ NMR spectra. The ${ }^{1} \mathrm{H}$ NMR spectra in DMSO- $d_{6}$ contained four signals at 0.95 (triplet), 1.66 (multiplet), 3.43 (multiplet) and $3.84 \mathrm{ppm}$ (singlet), which were attributed to $n$-propyl and cyclic methylene groups attached to nitrogen, respectively. However, there were only three apparent signals in the ${ }^{13} \mathrm{C} N M R$ spectrum. Another extremely broad signal at around $57.5 \mathrm{ppm}$ was also observed, but we were not able to assign it to the compound. In order to avoid possible overlapping of the missing signal with the solvent signal and reveal the character of the broad signal, the sample was 
dissolved in $\mathrm{D}_{2} \mathrm{O}$ and measured on a $500 \mathrm{MHz}$ spectrometer. The ${ }^{1} \mathrm{H}$ spectrum in $\mathrm{D}_{2} \mathrm{O}$ was very similar to that observed in DMSO- $d_{6}$ at $300 \mathrm{MHz}$, however four ${ }^{13} \mathrm{C}$ signals were definitively observed. By comparing the ${ }^{1} \mathrm{H}$ and ${ }^{13} \mathrm{C}$ chemical shifts with literature data, we concluded that compound $\mathbf{3}$ was 1,1,4,4-tetrapropylpiperazinium diiodide. Firstly, 1,1,4,4tetraethylpiperazinium dication was characterized by ${ }^{1} \mathrm{H}$ signals observed at 1.37 (triplet), 3.66 (quartet) and $3.92 \mathrm{ppm}$ (singlet). ${ }^{19}$ However, proton signals in 1,1-diethylaziridium cation were observed at 1.36 (triplet), 3.08 (singlet) and 3.28 (quartet) ppm. ${ }^{19}$ Thus, the chemical shift of the singlet signal assigned to ring methylene protons is a clue to discriminate between the 3- or 6membered rings. We observed the signal in the range typical of piperazinium species which was also supported by ${ }^{13} \mathrm{C}$ chemical shifts reported recently. ${ }^{20}$ Secondly, the presence of aziridinium species was excluded by measuring ${ }^{1} J_{\mathrm{CH}}$ values. Methylene groups in aziridine and aziridinium derivatives have very large ${ }^{1} J_{\mathrm{CH}}$ values of about $170 \mathrm{~Hz} \cdot{ }^{21,22}$ We observed significantly lower values of 145 (DMSO- $\left.d_{6}\right)$ and $148 \mathrm{~Hz}\left(\mathrm{D}_{2} \mathrm{O}\right)$, respectively. The broadening observed for the methylene carbon attached to $\mathrm{N}$ is likely due to a piperazinium conformational isomerization. ${ }^{23,24}$ This chair-to-chair exchange is relatively fast at $27^{\circ} \mathrm{C}$, the temperature of NMR measurements, thus detection of the signal is difficult. It is also responsible for the rather complex splitting pattern of n-propyl methylene protons and the single signal observed for axial and equatorial protons of the piperazine ring. ${ }^{25}$

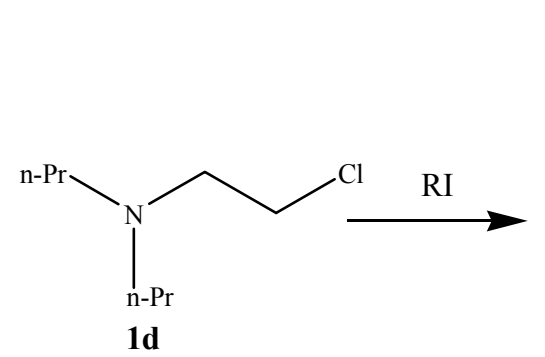

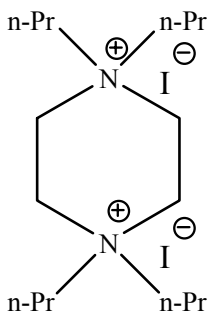

3

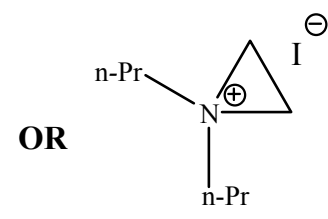

7

Scheme 2. The competitive cyclization.

The preparation of the isopropyl derivatives by the simple alkylation reaction under conditions of the Method A also failed. At this stage the necessity of an alternative methodology emerged. Method B was developed on the basis of experience with the alkylation reaction by Method A. Method B consists of three steps (Scheme 3 - Method B). The first step is the alkylation of 2-(dialkylamino)ethanols 4 with an appropriate iodoalkane. The obtained aminium iodides 5 were converted to aminium chlorides by freshly precipitated silver chloride. The isolated and properly dried aminium chlorides were then directly treated with thionyl chloride in a chloroform solution under cooling to afford the final derivatives of 2-chloro- $N, N, N$ trialkylethanaminium chlorides 6. 


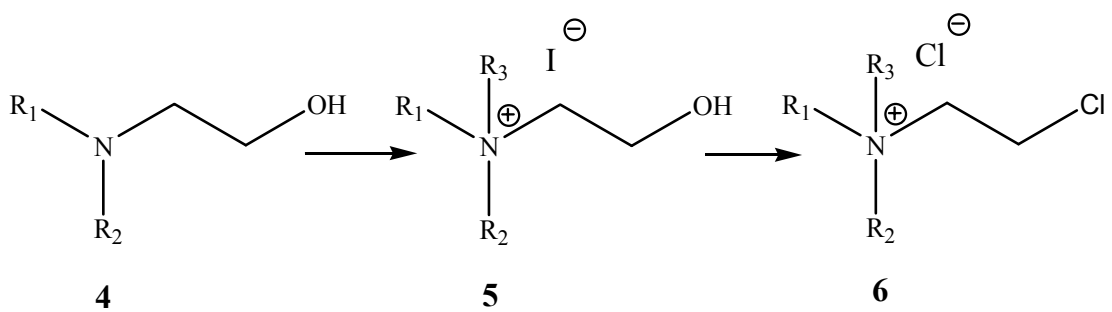
d) $\mathrm{R}_{1}=\mathrm{n}-\mathrm{Pr}, \mathrm{R}_{2}=\mathrm{n}-\mathrm{Pr}$
o) $\mathrm{R}_{1}=\mathrm{n}-\mathrm{Pr}, \mathrm{R}_{2}=\mathrm{n}-\mathrm{Pr}, \mathrm{R}_{3}=\mathrm{Et}$
u) $R_{1}=i \operatorname{Pr}, R_{2}=n-P r, R_{3}=M e$
k) $\mathrm{R}_{1}=\mathrm{iPr}, \mathrm{R}_{2}=\mathrm{Me}$
p) $\mathrm{R}_{1}=\mathrm{n}-\mathrm{Pr}, \mathrm{R}_{2}=\mathrm{n}-\mathrm{Pr}, \mathrm{R}_{3}=\mathrm{n}-\mathrm{Pr}$
v) $R_{1}=i \operatorname{Pr}, R_{2}=n-P r, R_{3}=E t$
1) $R_{1}=i \operatorname{Pr}, R_{2}=E t$
r) $R_{1}=i P r, R_{2}=M e, R_{3}=M e$
w) $R_{1}=i \operatorname{Pr}, R_{2}=i \operatorname{Pr}, R_{3}=M e$
m) $R_{1}=i P r, R_{2}=n-P r$
s) $R_{1}=i P r, R_{2}=E t, R_{3}=M e$
z) $R_{1}=i \operatorname{Pr}, R_{2}=i \operatorname{Pr}, R_{3}=E t$
n) $R_{1}=i \operatorname{Pr}, R_{2}=i \operatorname{Pr}$
t) $R_{1}=i \operatorname{Pr}, R_{2}=E t, R_{3}=E t$

Scheme 3. Method B.

The first two intermediates prepared by the Method B were the aminium iodides $5 \mathbf{5 0}$ and $\mathbf{5 p}$. While the alkylation reaction of the similar starting compound $N$-(2-chloroethyl)- $N$ propylpropan-1-amine 1d does not proceed to 2-chloroethan- $N, N, N$-trialkylaminium salts $\mathbf{2}$ at elevated temperature due to cyclization, the use of 2-(dipropylamino)ethanol $\mathbf{4} \mathbf{d}^{13,15}$ as a starting material completely eliminated this competitive reaction. It was therefore possible to carry out the alkylation reaction in refluxing acetone providing aminium iodides 50 and $\mathbf{5 p}$ in very good purity and with yields $>70 \%$.

The 2-(dialkylamino)ethanols $\mathbf{4}$ bearing at least one isopropyl group were treated with a twofold excess of iodoalkanes in butan-2-one at ambient temperature or, when using bulkier substituents, the temperature was elevated. This first step of the synthesis is actually the limitation of the Method B. Here, the influence of steric hindrance on the alkylation reaction could be clearly demonstrated. The different reactivity of 2-( $N$-propyl- $N$-isopropylamino)ethanol $\mathbf{4 m}^{13,15}$ with iodomethane and iodoethane is obvious. In the first case ambient temperature is sufficient to provide aminium iodide $\mathbf{5 u}$ in $91 \%$ yield, while the alkylation reaction with iodoethane carried out at the elevated temperature results in the formation of the aminium iodide 5v with a yield of only 56\%. Another example is the alkylation reaction of 2-(N,Ndiisopropylamino)ethanol $\mathbf{4 n}$ where greater steric hindrance causes a greater drop in reactivity than in the previous case. However, while the reaction with iodomethane over 7 hours proceeds smoothly at elevated temperature affording aminium iodide $\mathbf{5 w}$ in $93 \%$ yield, the alkylation with iodoethane at the same temperature is very slow. In this case the reaction mixture has to be heated for 60 hours to furnish only $15 \%$ of aminium iodide $5 z$. An attempt to alkylate 2-(N,Ndiisopropylamino)ethanol $4 \mathbf{n}$ with 1-iodopropane or 2-iodopropane was not successful under these conditions because the undesirable dehydrohalogenation of iodoalkanes occurs. Although only the aminium iodide $\mathbf{5 v}$ has not yet been reported, references to the other aminium iodide derivatives $\mathbf{5 o},{ }^{26} \mathbf{5 p},{ }^{26} \mathbf{5 r},{ }^{27} \mathbf{5 s},{ }^{27} \mathbf{5 t},{ }^{28} \mathbf{5 u},{ }^{13,15} \mathbf{5} \mathbf{w}^{27}$ and $\mathbf{5} \mathbf{z}^{27}$ are available. Since some of these compounds are not usually adequately described with regard to their characteristic data and some preparation procedures were not described in detail or a different synthesis was reported, we 
publish complete set of data in this paper . Melting points have not been measured considering the very high hygroscopic nature of the aminium iodides $\mathbf{5}$ which would certainly result in poor reproducibility of measurements.

The next step of the conversion of aminium iodides 5 to aminium chlorides by treatment with freshly precipitated silver chloride has to precede the final step of Method B otherwise the decomposition of derivatives $\mathbf{5}$ is accompanied by the evolution of iodine. This conversion provided excellent yields (95-99\%) and the resulting aminium chlorides were, after isolation and drying to constant weight, used for the reaction with thionyl chloride.

The last step of the Method B is the standard procedure for transforming alcohols to alkyl chlorides. Thionyl chloride was added under cooling to a solution of the aminium chloride $\mathbf{5}$ in anhydrous chloroform and then the reaction mixture was heated for one and half hours furnishing the desired 2-chloro- $N, N, N$-trialkylethanaminium chlorides 6 in a very good yield (69-86\%). All derivatives 6 are novel compounds except for $N$-(2-chloroethyl)- $N, N$-dimethylpropan-2-aminium chloride $\mathbf{6} \mathbf{r}^{29}$ which has already been reported.

\section{Conclusions}

Derivatives of $N, N, N$-trialkylaminium salts $\mathbf{2}, \mathbf{6}$ and related hydroxy analogues $\mathbf{5}$ which can be used as standards for the HPLC-MS analytical methods to monitor precursors of some potential chemical warfare agent have been synthesised. In one method, direct alkylation of 2-chloro- $\mathrm{N}, \mathrm{N}$ dialkylethanamine 1 was used but some limitations caused by steric hindrance were found. An alternative three-step methodology starting from 2-(dialkylamino)ethanols 4 enabled us to prepare derivatives with bulkier substituents.

\section{Experimental Section}

General Procedures. Melting points were determined on a Boetius stage and are uncorrected. The IR spectra were recorded in $\mathrm{KBr}$ wafers on an ATI Unicam Genesis FTIR instrument. The NMR spectra were recorded on a Bruker Avance 300 spectrometer and Bruker Avance 500 respectively; chemical shifts are reported in ppm, and coupling constants $J$ in Hz. Chemical shifts were externally referenced to TMS. Elemental analyses were performed with an EA 1108 Elemental Analyser (Fison Instruments). Mass spectra were taken using an LCQ ion trap mass spectrometer (Finnigan MAT, San Jose, CA, USA).

\section{Method A. Alkylation of 2-chloro- $N$, $N$-dialkylethanamines (1)}

A mixture of 2-chloro- $N, N$-dialkylethanaminium chloride 1 ( $25 \mathrm{mmol})$, crushed ice $(10 \mathrm{~g})$, icecold ether $(25 \mathrm{ml})$ and ice-cold $20 \%$ aqueous sodium hydroxide $(5 \mathrm{ml})$ was stirred vigorously for 5 minutes. The ether layer was decanted and the aqueous layer extracted with ice-cold ether 
$(2 \times 15 \mathrm{ml})$. The combined extracts were dried for 30 minutes at $4{ }^{\circ} \mathrm{C}$ over $\mathrm{MgSO}_{4}$. Drying agent was removed by filtration and ether removed in vacuo, yielding 70-85\% of a colorless oil. These 2-chloro- $N, N$-dialkylethanamines $\mathbf{1}$ are unstable on storage at room temperature and should be used immediately.

To the freshly prepared 2-chloro- $N, N$-dialkylethanamine 1 , acetone $(15 \mathrm{ml})$, diethyl ether $(25 \mathrm{ml})$ and the corresponding iodoalkane $(18 \mathrm{mmol})$ were added. The reaction mixture was stirred at the ambient temperature for 72 hours. The precipitated crystalline solid was washed with ether and recrystallized from a mixture of acetone-methanol.

2-Chloro- $\boldsymbol{N}$-ethyl- $\boldsymbol{N}, \boldsymbol{N}$-dimethylethanaminium iodide (2e). Prepared from 2-chloro- $N, N$ dimethylethanamine 1a and iodoethane. Yield: $56 \%$, mp: $196-197{ }^{\circ} \mathrm{C} \mathrm{dec} .\left(198^{\circ} \mathrm{C}^{16}\right)$, IR: 2985 ; $2952 ; 2882 ; 1450 ; 1020 ; 814 ; 773$. MS (ESI, $m / z): 136.1$. 1H NMR (300 MHz, DMSO- $\left.d_{6}\right): \delta$ $1.28(\mathrm{t}, 3 \mathrm{H}, J=7.0) ; 3.17(\mathrm{~s}, 6 \mathrm{H}$;); 3.51 (q, 2H, $J=7.0), 3.76(\mathrm{t}, 2 \mathrm{H}, J=7.1) ; 4.11(\mathrm{t}, 2 \mathrm{H}, J=$ 7.1). 13C NMR (75 MHz, DMSO- $d 6): \delta 8.0 ; 36.1 ; 49.8 ; 59.4 ; 62.3 . \mathrm{C}_{6} \mathrm{H}_{15} \mathrm{ClIN}$ (263.5) calculated: C, 27.34; H, 5.74; N, 5.31; found: C, 27.24; H, 5.73; N, 5.27.

$\boldsymbol{N}$-(2-Chloroethyl)- $\boldsymbol{N}, \boldsymbol{N}$-dimethylpropan-1-aminium iodide (2f). Prepared from 2-chloro- $N, N$ dimethylethanamine 1a and iodopropane. Yield: $44 \%$, mp: 208-210 ${ }^{\circ} \mathrm{C}$ dec., IR: 3006; 2961; $2875 ; 1483 ; 1040 ; 882 ; 753$. MS (ESI, $m / z): 150.1$. $\left.1 \mathrm{H} \mathrm{NMR} \mathrm{(300} \mathrm{MHz,} \mathrm{DMSO-} d_{6}\right): \delta 0.92(\mathrm{t}$, $3 \mathrm{H}, J=7.0) ; 1.73(\mathrm{hx}, 2 \mathrm{H}, J=7.0) ; 3.17(\mathrm{~s}, 6 \mathrm{H}) ; 3.39-3.43(\mathrm{~m}, 2 \mathrm{H},) ; 3.79(\mathrm{t}, 2 \mathrm{H}, J=7.1) ; 4.12$ $(\mathrm{t}, 2 \mathrm{H}, J=7.1)$. 13C NMR (75 MHz, DMSO- $\left.d_{6}\right): \delta 10.1 ; 15.3 ; 36.1 ; 50.3 ; 62.8 ; 64.9 . \mathrm{C}_{7} \mathrm{H}_{17} \mathrm{ClIN}$ (277.6) calculated: C, 30.29; H, 6.17; N, 5.05; found: C, 30.34; H, 6.04; N, 5.14.

$\boldsymbol{N}$-(2-Chloroethyl)- $\boldsymbol{N}$-ethyl- $\boldsymbol{N}$-methylpropan-1-aminium iodide (2g). Prepared from $\mathrm{N}$-(2chloroethyl)- $N$-ethylpropan-1-amine 1c and iodomethane. Yield: $56 \%, \mathrm{mp}: 209-210^{\circ} \mathrm{C} \mathrm{dec}$. (aceton / methanol), IR: 2988; 2971; 2881; 1445; 1015; 816; 753. MS (ESI, m/z): 164.2. 1H NMR (300 MHz, DMSO- $\left.d_{6}\right): \delta 0.92(\mathrm{t}, 3 \mathrm{H}, J=7.3) ; 1.26$ (t, 3H, $\left.J=7.2\right) ; 1.69(\mathrm{hx}, 2 \mathrm{H}, J=7.3)$; $3.11(\mathrm{~s}, 3 \mathrm{H}) ; 3.33-3.37$ (m, 2H,); 3.47 (q, 2H, $J=7.2) ; 3.73$ (t, 2H, $J=7.1) ; 4.11$ (t, 2H, $J=7.1)$. 13C NMR (75 MHz, DMSO- $\left.d_{6}\right): \delta 7.6 ; 10.2 ; 15.0 ; 35.9 ; 47.4 ; 56.8 ; 60.1 ; 61.6 . \mathrm{C}_{8} \mathrm{H}_{19} \mathrm{ClIN}$ (291.6) calculated: C, 32.95; H, 6.57; N, 4.80; found: C, 32.90; H, 6.56; N, 4.59.

2-Chloro- $\boldsymbol{N}, \boldsymbol{N}$-diethyl- $\boldsymbol{N}$-methylethanaminium iodide (2h). Prepared from 2-chloro- $N, N$ diethylethanamine $\mathbf{1 b}$ and iodomethane. Yield: $49 \%$, mp: $227-229{ }^{\circ} \mathrm{C} \mathrm{dec} .\left(219-220{ }^{\circ} \mathrm{C}^{18}\right)$, IR: $2983 ; 2953 ; 2878 ; 1451 ; 1010 ; 805 ; 763$. MS (ESI, $m / z): 150.2$. 1H NMR (300 MHz, DMSO$\left.d_{6}\right): \delta 1.23(\mathrm{t}, 6 \mathrm{H}, J=7.2), 3.09(\mathrm{~s}, 3 \mathrm{H}) ; 3.46(\mathrm{q}, 4 \mathrm{H}, J=7.2) ; 3.71(\mathrm{t}, 2 \mathrm{H}, J=7.1) ; 4.10(\mathrm{t}, 2 \mathrm{H}, J$ $=7.1) .13 \mathrm{C} \mathrm{NMR}\left(75 \mathrm{MHz}, \mathrm{DMSO}-d_{6}\right): \delta 7.6 ; 35.9 ; 46.9 ; 56.1 ; 59.6 . \mathrm{C}_{7} \mathrm{H}_{17} \mathrm{ClIN}$ (277.6) calculated C, 30.29; H, 6.17; N, 5.05; found: C, 30.39; H, 6.06; N, 5.16.

$\boldsymbol{N}$-(2-Chloroethyl)- $\mathbf{N}, \mathbf{N}$-diethylpropan-1-aminium iodide (2i). Prepared from 2-chloro- $N, N$ diethylethanamine 1b and iodopropane. Yield: $51 \%$, mp: $256-258{ }^{\circ} \mathrm{C}$ dec., IR: 2977; 2840; 1438; 1015; 897; 815. MS (ESI, $m / z): 178.2$. 1H NMR (300 MHz, DMSO- $\left.d_{6}\right): \delta 0.92(\mathrm{t}, 3 \mathrm{H}, J=$ $7.0) ; 1.23$ ( t, $6 \mathrm{H}, J=7.2), 1.66(\mathrm{hx}, 2 \mathrm{H}, J=7.0) ; 3.33-3.37(\mathrm{~m}, 2 \mathrm{H}) ; 3.49(\mathrm{t}, 4 \mathrm{H}, J=7.2) ; 3.72$ $(\mathrm{t}, 2 \mathrm{H}, J=7.1), 4.19$ (t, 2H, $J=7.1)$. 13C NMR (75 MHz, DMSO-d $): \delta 7.4 ; 10.2 ; 14.8 ; 36.0$; 53.2; 56.8; 58.5. $\mathrm{C}_{9} \mathrm{H}_{21} \mathrm{ClIN}$ (305.6) calculated: $\mathrm{C}, 35.37 ; \mathrm{H}, 6.93 ; \mathrm{N}, 4.58$; found: $\mathrm{C}, 35.29$; $\mathrm{H}$, $7.02 ; \mathrm{N}, 4.67$. 
$\boldsymbol{N}$-(2-Chloroethyl)- $\boldsymbol{N}$-methyl- $N$-propylpropan-1-aminium iodide (2j). Prepared from $N$-(2chloroethyl)- $N$-propylpropan-1-amine 1d and iodomethane. Yield: $51 \%$, mp: $212{ }^{\circ} \mathrm{C} \mathrm{dec}$. (aceton / methanol), IR: 2971; 2943; 2876; 1476; 1055; 944; 755. MS (ESI, m/z): 178.2. $1 \mathrm{H}$ NMR (300 MHz, DMSO-d $): \delta 0.91$ (t, 6H, $J=7.0) ; 1.69(\mathrm{hx}, 4 \mathrm{H}, J=7.0) ; 3.10(\mathrm{~s}, 3 \mathrm{H}) ; 3.26-$ $3.31(\mathrm{~m}, 4 \mathrm{H}) ; 3.72(\mathrm{t}, 2 \mathrm{H}, J=7.1) ; 4.11(\mathrm{t}, 2 \mathrm{H}, J=7.1)$. 13C NMR (75 MHz, DMSO- $\left.d_{6}\right): \delta 10.2$; $15.0 ; 35.9 ; 47.9 ; 60.6 ; 62.4 . \mathrm{C}_{9} \mathrm{H}_{21} \mathrm{ClIN}(305.6)$ calculated: $\mathrm{C}, 35.37 ; \mathrm{H}, 6.93 ; \mathrm{N}, 4.58$; found: $\mathrm{C}$, $35.42 ; \mathrm{H}, 6.83 ; \mathrm{N}, 4.64$.

\section{Competitive cyclization. 1,1,4,4-Tetrapropylpiperazinium diiodide (3)}

A mixture of $N$-(2-chloroethyl)- $N$-propylpropan-1-amine 1d (12 mmol), iodoethane or iodopropane $(48 \mathrm{mmol})$ in acetone $(15 \mathrm{ml})$ was refluxed for 12 hours then to a cooled mixture was added ether $(30 \mathrm{ml})$ and precipitated crystalline compound was filtered off. Yield: 59\%, mp: 249-250 ${ }^{\circ} \mathrm{C}$ dec. (methanol), IR: 2965; 2947; 2879; 1486; 1270; 940; 760. MS (ESI, m/z): 128.2. $1 \mathrm{H}$ NMR (300 MHz, DMSO-d $): \delta 0.95\left(\mathrm{t}, 12 \mathrm{H}, J=7.0 \mathrm{~Hz}, \mathrm{CH}_{3}\right) ; 1.58-1.74\left(\mathrm{~m}, 8 \mathrm{H}, \mathrm{CH}_{3} \mathrm{CH}_{2}\right)$; 3.47-3.60 (m, 8H, $\left.\mathrm{CH}_{2} \mathrm{~N}\right) ; 3.84\left(\mathrm{~s}, 8 \mathrm{H}\right.$, piperazinium $\left.\mathrm{CH}_{2}\right)$. 13C NMR (75 MHz, DMSO- $\left.d_{6}\right): \delta$ $10.2\left(\mathrm{CH}_{3}\right) ; 14.5\left(\mathrm{CH}_{3} \mathrm{CH}_{2}\right) ; 51.5$ (piperazinium $\left.\mathrm{CH}_{2}\right) ; 57.5\left(\mathrm{CH}_{2} \mathrm{~N}\right)$. $1 \mathrm{H}$ NMR $\left(500 \mathrm{MHz}, \mathrm{D}_{2} \mathrm{O}\right)$ : $\delta 0.98\left(\mathrm{t}, 12 \mathrm{H}, J=7.3 \mathrm{~Hz} \mathrm{CH}\right.$ ); $1.68-1.83\left(\mathrm{~m}, 8 \mathrm{H}, \mathrm{CH}_{3} \mathrm{CH}_{2}\right) ; 3.44-3.55\left(\mathrm{~m}, 8 \mathrm{H}, \mathrm{CH}_{2} \mathrm{~N}\right) ; 3.91(\mathrm{~s}$, $8 \mathrm{H}$, piperazinium $\left.\mathrm{CH}_{2}\right)$. $13 \mathrm{C}$ NMR $\left(125 \mathrm{MHz}, \mathrm{D}_{2} \mathrm{O}\right): \delta 9.2\left(\mathrm{CH}_{3}\right) ; 14.3\left(\mathrm{CH}_{3} \mathrm{CH}_{2}\right) ; 51.6$ (piperazinium $\left.\mathrm{CH}_{2}\right) ; 60.2\left(\mathrm{CH}_{2} \mathrm{~N}\right) . \mathrm{C}_{16} \mathrm{H}_{36} \mathrm{I}_{2} \mathrm{~N}_{2}$ (510.3) calculated: C, 37,66; H, 7,11; N, 5,49; found: C, 37.94; H, 7.40; N, 5.58.

\section{Method B. Alkylation of 2-(dialkylamino)ethanols (4)}

The corresponding 2-(dialkylamino)ethanol 4 was mixed together with the corresponding halogenalkane in anhydrous acetone or butan-2-one at the ambient temperature. The reaction mixture was stirred at the ambient or elevated temperature for several hours and then allowed to cool down. The precipitated solid arose from the standing of the reaction mixture in a fridge ($20^{\circ} \mathrm{C}$ ) overnight was filtered-off and washed with a small portion of a mixture acetone-diethyl ether $(1: 2)$.

$\boldsymbol{N}$-(2-Chloroethyl)- $\boldsymbol{N}$-ethyl- $\boldsymbol{N}$-propylpropan-1-aminium iodide (5o). 2-(dipropylamino)ethanol 4d $(10.0 \mathrm{~g}, 0.069 \mathrm{~mol})$ and iodoethane $(11.3 \mathrm{ml}, 0.140 \mathrm{~mol})$ in acetone $(35 \mathrm{ml})$, reflux 20 hours. Yield: 77 \%, IR: 3315; 2967; 2942; 2883; 1470; 1061; 743. MS (ESI, m/z): 174.2. 1H NMR (300 MHz, DMSO- $\left.d_{6}\right): \delta 0.89$ (t, 6H, $\left.J=7.2\right) ; 1.19$ (t, 3H, $\left.J=7.2\right), 1.62(\mathrm{hx}, 4 \mathrm{H}, J=7.2)$; 3.16-3.22 (m, 2H); 3.32-3.39 (m, 4H); $3.77(\mathrm{bs}, 2 \mathrm{H}) ; 5.18(\mathrm{bs}, 1 \mathrm{H}, \mathrm{OH})$. 13C NMR (75 MHz, DMSO- $\left.d_{6}\right): \delta 7.3 ; 10.4 ; 14.7 ; 53.8 ; 54.4 ; 58.8 ; 59.2$. $\mathrm{C}_{10} \mathrm{H}_{24} \mathrm{INO}(301.2)$ calculated: $\mathrm{C}, 39.88 ; \mathrm{H}$, 8.03; N, 4.65; found: C, 39.93; H, 8.24; N, 4.46 .

$\mathbf{N}$-(2-Chloroethyl)- $\mathbf{N}, \boldsymbol{N}$-dipropylpropan-1-aminium iodide (5p). 2-(dipropylamino)ethanol 4d (10.3 g, $0.071 \mathrm{~mol})$ and 1-iodopropane $(24 \mathrm{~g}, 0.142 \mathrm{~mol})$ in acetone $(50 \mathrm{ml})$, reflux for 30 hours. Yield: 73 \%, IR: 3314; 2969; 2940; 2881; 1468; 1057; 751. MS (ESI, $m / z): 188.2$. 1H NMR (300 MHz, DMSO- $\left.d_{6}\right): \delta 0.88(\mathrm{t}, 9 \mathrm{H}, J=7.2) ; 1.63(\mathrm{hx}, 6 \mathrm{H}, J=7.2) ; 3.18-3.23(\mathrm{~m}, 6 \mathrm{H}) ; 3.34(\mathrm{t}, 2 \mathrm{H}, J$ $=5.4) ; 3.79(\mathrm{bs}, 2 \mathrm{H}) ; 5.18(\mathrm{bs}, 1 \mathrm{H}, \mathrm{OH}) .13 \mathrm{C}$ NMR (75 MHz, DMSO- $\left.d_{6}\right): \delta 10.4 ; 14.8 ; 54.4$; 
59.5; 59.8. $\mathrm{C}_{11} \mathrm{H}_{26} \mathrm{INO}(315.2)$ calculated: $\mathrm{C}, 41.91 ; \mathrm{H}, 8.31 ; \mathrm{N}, 4.44$; found: $\mathrm{C}, 41.78 ; \mathrm{H}, 8.50 ; \mathrm{N}$, 4.36 .

$\boldsymbol{N}$-(2-Chloroethyl)- $\mathbf{N}, \mathbf{N}$-dimethylpropan-2-aminium iodide (5r). 2-[isopropyl(methyl)amino]ethanol 4k (8.08 g; 0,069 mol) and iodomethane $(0,138 \mathrm{~mol})$ in butan-2-one $(35 \mathrm{ml})$, stirred at ambient temperature for 24 hours. Yield: $84 \%$, IR: 3340; 2992; 2904; 1475; 1418; 1084; 1046; 668. MS (ESI, $m / z): 132.1$. 1H NMR (300 MHz, DMSO- $\left.d_{6}\right): \delta 1.29$ (d, $6 \mathrm{H}, J=6.6$ ); 2.99 (s, 6H); 3.66 (t, 2H, $J=5.6) ; 3.76$ (septet, $1 \mathrm{H}, J=6.6) ; 3.83$ (bs, 2H); 5.20 (bs, 1H, OH). 13C NMR (75 MHz, DMSO- $\left.d_{6}\right): \delta 15.9 ; 47.7 ; 54.8 ; 62.7 ; 65.2 . \mathrm{C}_{7} \mathrm{H}_{18} \mathrm{INO}(259.1)$ calculated: $\mathrm{C}$, 32.45; H, 7.00; N, 5.41; found: C, 32.36; H, 7.12; N, 5.30.

$\boldsymbol{N}$-Ethyl- $\boldsymbol{N}$-(2-hydroxyethyl)- $\boldsymbol{N}$-methylpropan-2-aminium iodide (5s). 2-[ethyl(isopropyl)amino]ethanol $4 \mathrm{l}(9.05 \mathrm{~g}, 0.069 \mathrm{~mol})$ and iodomethane $(0.138 \mathrm{~mol})$ in butan-2-one $(35 \mathrm{ml})$, stirred at ambient temperature for 24 hours. Yield: $87 \%$, IR: 3320; 2990; 2897; 1460; 1402; 1081; 1048; 669. MS (ESI, $m / z): 146.1$. 1H NMR (300 MHz, DMSO- $\left.d_{6}\right): \delta 1.22$ (t, $3 \mathrm{H}, J=7.2$ ); $1.28(\mathrm{~d}, 6 \mathrm{H}, J=6.6) ; 2.91(\mathrm{~s}, 3 \mathrm{H}) ; 3.30-3.42(\mathrm{~m}, 4 \mathrm{H}) ; 3.74-3.83(\mathrm{~m}, 3 \mathrm{H}) ; 5.18(\mathrm{bs}, 1 \mathrm{H}, \mathrm{OH}) .13 \mathrm{C}$ NMR (75 MHz, DMSO- $\left.d_{6}\right): \delta 7.7 ; 15.7 ; 44.2 ; 54.4 ; 54.6 ; 59.0 ; 63.0 . \mathrm{C}_{8} \mathrm{H}_{20} \mathrm{INO}$ (273.2) calculated: C, 35.18; H, 7.38; N, 5.13; found: C, 35.03; H, 7.52; N, 5.18.

$\boldsymbol{N}, \mathbf{N}$-Diethyl- $\boldsymbol{N}$-(2-hydroxyethyl)propan-2-aminium iodide (5t). 2-[ethyl(isopropyl)amino]ethanol $4 \mathrm{l}(9.05 \mathrm{~g}, 0.069 \mathrm{~mol})$ and iodoethane $(0.138 \mathrm{~mol})$ in butan-2-one $(35 \mathrm{ml})$, reflux for 24 hours. Yield: 48 \%, IR: 3310; 2983; 2892; 1455; 1406; 1045; 762. MS (ESI, m/z): 160.2. 1H NMR (300 MHz, DMSO-d $\left.)_{6}\right): \delta 1.23(\mathrm{t}, 6 \mathrm{H}, J=7.2) ; 1.33(\mathrm{~d}, 6 \mathrm{H}, J=6.6) ; 3.32(\mathrm{t}, 2 \mathrm{H}, J=$ 5.4); 3.40 (q, $4 \mathrm{H}, J=7.2) ; 3.73-3.82(\mathrm{~m}, 3 \mathrm{H}) ; 5.20$ (bs, 1H, OH). 13C NMR (75 MHz, DMSO$\left.d_{6}\right): \delta 8.8 ; 16.4 ; 52.7 ; 54.9 ; 57.9 ; 62.9 . \mathrm{C}_{9} \mathrm{H}_{22} \mathrm{INO}(287.2)$ calculated: $\mathrm{C}, 37.64 ; \mathrm{H}, 7.72 ; \mathrm{N}, 4.88$; found: C, 37.49; H, 7.85; N, 4.86 .

$\boldsymbol{N}$-(2-Hydroxyethyl)- $\boldsymbol{N}$-isopropyl- $\boldsymbol{N}$-methylpropan-1-aminium iodide (5u). 2-[isopropyl(propyl)amino]ethanol 4m (10.0 g, $0.069 \mathrm{~mol})$ and iodomethane $(0.138 \mathrm{~mol})$ in butan-2-one (35 $\mathrm{ml})$, stirred at ambient temperature for 30 hours. Yield: $91 \%$, IR: 3320; 2972; 2881; 1469; 1387 ; 1085; 939. MS (ESI, $m / z): 160.2$. $1 \mathrm{H}$ NMR (300 MHz, DMSO- $\left.d_{6}\right): \delta 0.89$ (t, $\left.3 \mathrm{H}, J=7.0\right) ; 1.28$ $(\mathrm{d}, 6 \mathrm{H}, J=6.6) ; 1.66(\mathrm{hx}, 2 \mathrm{H}, J=7.0) ; 2.95(\mathrm{~s}, 3 \mathrm{H}) ; 3.23-3.39(\mathrm{~m}, 4 \mathrm{H}) ; 3.74-3.83(\mathrm{~m}, 3 \mathrm{H}) ; 5.20$ (bs, 1H, OH). 13C NMR (75 MHz, DMSO-d $)$ : $\delta 10.5 ; 15.2 ; 15.7 ; 44.7 ; 54.5 ; 59 ; 7 ; 60.1 ; 63.4$. $\mathrm{C}_{9} \mathrm{H}_{22} \mathrm{INO}(287.2)$ calculated: C, 37.64; H, 7.72;N, 4.88; found: C, 37.50; H, 7.88; N, 4.71.

$\boldsymbol{N}$-Ethyl- $\boldsymbol{N}$-(2-hydroxyethyl)- $\boldsymbol{N}$-isopropylpropan-1-aminium iodide (5v). 2-[isopropyl(propyl)amino]ethanol 4m $(10.0 \mathrm{~g}, 0.069 \mathrm{~mol})$ and iodoethane $(0.138 \mathrm{~mol})$ in butan-2-one $(35$ $\mathrm{ml}$ ), reflux for 24 hours. Yield: $56 \%$, IR: 3320; 2974; 2880; 1469; 1408; 1085; 947. MS (ESI, $m / z): 174.2$. 1H NMR (300 MHz, DMSO- $\left.d_{6}\right): \delta 0.89$ (t, 3H, $\left.J=7.0\right) ; 1.23(\mathrm{t}, 3 \mathrm{H}, J=7.2) ; 1.32$ $(\mathrm{d}, 6 \mathrm{H}, J=6.6) ; 1.68(\mathrm{hx}, 2 \mathrm{H}, J=7.0) ; 3.22-3.46(\mathrm{~m}, 6 \mathrm{H}) ; 3.74-3.83(\mathrm{~m}, 3 \mathrm{H}) ; 5.20(\mathrm{bs}, 1 \mathrm{H}, \mathrm{OH})$. 13C NMR (75 MHz, DMSO- $\left.d_{6}\right): \delta 8.8 ; 10.7 ; 16.2 ; 16.5 ; 53.2 ; 54.9 ; 58.3 ; 58.6 ; 63.3 . \mathrm{C}_{10} \mathrm{H}_{24} \mathrm{INO}$ (301.2) calculated: C, 39.88; H, 8.03; N, 4.65; found: C, 39.96; H, 8.13; N, 4.61.

$\mathrm{N}$-(2-Hydroxyethyl)- $\boldsymbol{N}$-isopropyl- $\boldsymbol{N}$-methylpropan-2-aminium $\quad$ (5w). 2-(diisopropylamino)ethanol 4n (10.0 g, $0.069 \mathrm{~mol})$ and iodomethane $(0.138 \mathrm{~mol})$ in butan-2-one $(35 \mathrm{ml})$, reflux for 7 hours. Yield: 93 \%, IR: 3310; 2973; 2891; 1472; 1404; 1108; 1048; 751. MS (ESI, 
$m / z): 160.2$. 1H NMR (300 MHz, DMSO- $\left.d_{6}\right): \delta 1.32(\mathrm{~d}, 12 \mathrm{H}, J=6.6) ; 2.89(\mathrm{~s}, 3 \mathrm{H}) ; 3.33(\mathrm{t}, 2 \mathrm{H}$, $J=5.6$ ); 3.76 (bs, 2H); 3.88 (septet, 2H, $J=6.6$ ); 5.21 (bs, 1H, OH). 13C NMR (75 MHz, DMSO- $\left.d_{6}\right): \delta 16.6 ; 41.6 ; 55.1 ; 57.9 ; 63.4 . \mathrm{C}_{9} \mathrm{H}_{22} \mathrm{INO}(287.2)$ calculated: $\mathrm{C}, 37.64 ; \mathrm{H}, 7.72 ; \mathrm{N}$, 4.88; found: C, 37.58; H, 7.86; N, 4.69 .

$\mathrm{N}$-Ethyl- $\mathrm{N}$-(2-hydroxyethyl)- $\mathrm{N}$-isopropylpropan-2-aminium iodide (5z). 2-(diisopropylamino)ethanol 4n (10.0 g, $0.069 \mathrm{~mol})$ and iodoethane $(0.138 \mathrm{~mol})$ in butan-2-one $(35 \mathrm{ml})$, reflux for 60 hours. Yield: $15 \%$, IR: 3310; 2982; 2898; 1473; 1409; 1132; 1044; 739. MS (ESI, $\mathrm{m} / z)$ : 174.2. 1H NMR (300 MHz, DMSO- $\left.d_{6}\right): \delta 1.27(\mathrm{t}, 3 \mathrm{H}, J=7.2) ; 1.37(\mathrm{~d}, 12 \mathrm{H}, J=6.6) ; 3.35$ (t, $2 \mathrm{H}, J=5.6$ ); 3.44 (q, 2H, $J=7.2) ; 3.79$ (bs, 2H); 3.98 (septet, $2 \mathrm{H}, J=6.6$ ); 5.21 (bs, $1 \mathrm{H}, \mathrm{OH})$. 13C NMR (75 MHz, DMSO-d $): \delta 9.9 ; 17.9 ; 52.0 ; 55.2 ; 57.9 ; 62.2 . \mathrm{C}_{10} \mathrm{H}_{24} \mathrm{INO}(301.2)$ calculated: C, 39.88; H, 8.03; N, 4.65; found: C, 39.80; H, 8.16; N, 4.69.

\section{Conversion of aminium iodides (5) to aminium chlorides and subsequent treatment with thionyl chloride}

A solution of the corresponding aminium iodide $5(10 \mathrm{mmol})$ in water $(20 \mathrm{ml})$ was added with stirring to a freshly precipitated and washed silver chloride $(10.5 \mathrm{mmol})$ suspended in water $(30$ $\mathrm{ml}$ ). A suspension was stirred in dark without access of light for 6 hours. The resulting precipitate was filtered-off and the filtrate was evaporated under reduced pressure to dryness. Aminium chloride was dried in vacuo over phosphorus pentaoxide at $110{ }^{\circ} \mathrm{C}$ to a constant weight. Yields: 95-99\%.

A solution of the corresponding aminium iodide $(10 \mathrm{mmol})$ in anhydrous chloroform $(10 \mathrm{ml})$ was added with stirring and cooling $\left(0^{\circ} \mathrm{C}\right)$ to a solution of thionyl chloride $(8.4 \mathrm{mmol})$ in anhydrous chloroform $(2 \mathrm{ml})$. The resulting solution was refluxed for one and half hour and allowed to cool down, then methanol was added $(1 \mathrm{ml})$ and stirred for 15 minutes. Volatiles were evaporated and after that the solid residue was dissolved in methanol $(0.5 \mathrm{ml})$ and evaporated again to dryness. The crude product was recrystallized from a mixture of aceton-ether.

$\boldsymbol{N}$-(2-Chloroethyl)- $\boldsymbol{N}$-ethyl- $\boldsymbol{N}$-propylpropan-1-aminium chloride (6o). Yield: 75 \%, mp: 220$225^{\circ} \mathrm{C}$ dec., IR: 2871; 2949; 2878; 1458; 1024; 960; 749. MS (ESI, $\left.m / z\right): 192.2$. 1H NMR (300 MHz, DMSO- $\left.d_{6}\right): \delta 0.91(\mathrm{t}, 6 \mathrm{H}, J=7.0) ; 1.22(\mathrm{t}, 3 \mathrm{H}, J=7.3), 1.65(\mathrm{hx}, 4 \mathrm{H}, J=7.0) ; 3.29-3.34$ $(\mathrm{m}, 4 \mathrm{H}) ; 3.45$ (q, 2H, $J=7.3) ; 3.70(\mathrm{t}, 2 \mathrm{H}, J=7.1) ; 4.13(\mathrm{t}, 2 \mathrm{H}, J=7.1) .13 \mathrm{C}$ NMR $(75 \mathrm{MHz}$, DMSO- $\left.d_{6}\right): \delta 7.4 ; 10.3 ; 14.8 ; 35.9 ; 53.8 ; 57.4 ; 59.1 . \mathrm{C}_{10} \mathrm{H}_{23} \mathrm{Cl}_{2} \mathrm{~N}(228.2)$ calculated: $\mathrm{C}, 52.63 ; \mathrm{H}$, 10.16 ; N, 6.14; found: C, 52.74; H, 10.11; N, 6.17 .

$\boldsymbol{N}$-(2-Chloroethyl)- $\mathbf{N}, \boldsymbol{N}$-dipropylpropan-1-aminium chloride (6p). Yield: 69 \%, mp: 175$180^{\circ} \mathrm{C}$ dec., IR: 2971; 2951; 2879; 1472; 1024; 953; 747. MS (ESI, $\left.m / z\right): 206.3$. 1H NMR (300 MHz, DMSO- $\left.d_{6}\right): \delta 0.91(\mathrm{t}, 9 \mathrm{H}, J=7.0) ; 1.66(\mathrm{hx}, 6 \mathrm{H}, J=7.0) ; 3.28-3.33(\mathrm{~m}, 6 \mathrm{H}) ; 3.71(\mathrm{t}, 2 \mathrm{H}, J$ $=7.1) ; 4.13(\mathrm{t}, 2 \mathrm{H}, J=7.1)$. 13C NMR (75 MHz, DMSO- $\left.d_{6}\right): \delta 10.3 ; 14.9 ; 36.0 ; 58.0 ; 59.6$. $\mathrm{C}_{11} \mathrm{H}_{25} \mathrm{Cl}_{2} \mathrm{~N}$ (242.2) calculated: C, 54.54; H, 10.40; N, 5.78; found: C, 54.64; H, 10.31; N, 5.81.

$\boldsymbol{N}$-(2-Chloroethyl)- $\mathbf{N}, \boldsymbol{N}$-dimethylpropan-2-aminium (6r). Yield: $76 \%$, mp: $225-227{ }^{\circ} \mathrm{C} \mathrm{dec.,}$ IR: $2997 ; 2964 ; 1478 ; 1392 ; 1173 ; 1117 ; 764$. MS (ESI, $m / z): 150.1 .1 \mathrm{H} \mathrm{NMR} \mathrm{(300} \mathrm{MHz,}$ DMSO- $\left.d_{6}\right): \delta 1.30(\mathrm{~d}, 6 \mathrm{H}, J=6.6) ; 3.03(\mathrm{~s}, 6 \mathrm{H}) ; 3.68(\mathrm{t}, 2 \mathrm{H}, J=7.1) ; 3.76($ septet, $1 \mathrm{H}, J=6.6)$; 
4.09 (t, $2 \mathrm{H}, J=7.1)$. 13C NMR (75 MHz, DMSO- $\left.d_{6}\right): \delta 16.4 ; 37.4 ; 42.2 ; 56.4 ; 63.5 . \mathrm{C}_{7} \mathrm{H}_{17} \mathrm{Cl}_{2} \mathrm{~N}$ (186.1) calculated C, 45.17; H, 9.21; N, 7.53; found: C, 45.23; H, 9.36; N, 7.41.

$\boldsymbol{N}$-(2-Chloroethyl)- $\boldsymbol{N}$-ethyl- $\boldsymbol{N}$-methylpropan-2-aminium (6s). Yield: $86 \%$, mp: $193-195^{\circ} \mathrm{C}$ dec., IR: 2988; 2957; 1466; 1410; 1175; 1112; 755. MS (ESI, $m / z): 164.1$. 1H NMR (300 MHz, DMSO- $\left.d_{6}\right): \delta 1.22$ (t, $\left.3 \mathrm{H}, J=7.5\right) ; 1.29$ (d, $\left.6 \mathrm{H}, J=6.6\right) ; 2.99$ (s, 3H); 3.41 (q, $\left.2 \mathrm{H}, J=7.5\right) ; 3.63$ (t, 2H, $J=7.1$ ); 3.81 (septet, $1 \mathrm{H}, J=6.6$ ); 4.07 (t, 2H, $J=7.1$ ). 13C NMR (75 MHz, DMSO- $d_{6}$ ): $\delta 7.7 ; 15.6 ; 36.1 ; 43.9 ; 54.3 ; 57.4 ; 63.2 . \mathrm{C}_{8} \mathrm{H}_{19} \mathrm{Cl}_{2} \mathrm{~N}(200.1)$ calculated: $\mathrm{C}, 48.01 ; \mathrm{H}, 9.57 ; \mathrm{N}$, 7.00; found: C, 48.09; H, 9.53; N, 7.12.

$\mathrm{N}$-(2-Chloroethyl)- $\mathrm{N}, \mathrm{N}$-diethylpropan-2-aminium (6t). Yield: $80 \%$, mp: $182-185{ }^{\circ} \mathrm{C} \mathrm{dec}$., IR: 2986; 2947; 2896; 1461; 1409; 1145; 747. MS (ESI, $m / z)$ : 178.1. 1H NMR (300 MHz, DMSO$\left.d_{6}\right): \delta 1.23(\mathrm{t}, 6 \mathrm{H}, J=7.2) ; 1.33(\mathrm{~d}, 6 \mathrm{H}, J=6.6) ; 3.41-3.50(\mathrm{~m}, 4 \mathrm{H}) ; 3.63(\mathrm{t}, 2 \mathrm{H}, J=7.1) ; 3.81$ (septet, $1 \mathrm{H}, J=6.6) ; 4.08(\mathrm{t}, 2 \mathrm{H}, J=7.1)$. 13C NMR (75 MHz, DMSO- $\left.d_{6}\right): \delta 8.8 ; 16.5 ; 36.6$; 52.5; 56.3; 63.2. $\mathrm{C}_{9} \mathrm{H}_{21} \mathrm{Cl}_{2} \mathrm{~N}$ (214.2) calculated: $\mathrm{C}, 50.47 ; \mathrm{H}, 9.88 ; \mathrm{N}, 6.54$; found: $\mathrm{C}, 50.39 ; \mathrm{H}$, $9.98 ; \mathrm{N}, 6.49$.

$\boldsymbol{N}$-(2-Chloroethyl)- $\boldsymbol{N}$-isopropyl- $\boldsymbol{N}$-methylpropan-1-aminium (6u). Yield: 79 \%, mp: 222-224 ${ }^{\circ} \mathrm{C}$ dec., IR: 2967; 2877; 1476; 1389; 756. MS (ESI, $\left.m / z\right)$ : 178.2. 1H NMR (300 MHz, DMSO$\left.d_{6}\right): \delta 0.90(\mathrm{t}, 3 \mathrm{H}, J=7.2) ; 1.29(\mathrm{~d}, 6 \mathrm{H}, J=6.6) ; 1.66(\mathrm{hx}, 2 \mathrm{H}, J=7.2) ; 3.02(\mathrm{~s}, 3 \mathrm{H}) ; 3.25-3.31$ (m, 2H); 3.65 (t, 2H, $J=7.1$ ); 3.81 (septet, $1 \mathrm{H}, J=6.6$ ); 4.09 (t, 2H, $J=7.1$ ). 13C NMR (75 MHz, DMSO- $\left.d_{6}\right): \delta 10.4 ; 15.2 ; 17.6 ; 36.2 ; 44.5 ; 57.9 ; 59.9 ; 63.7 . \mathrm{C}_{9} \mathrm{H}_{21} \mathrm{Cl}_{2} \mathrm{~N}(214.2)$ calculated: C, 50.47; H, 9.88; N, 6.54; found: C, 50.42; H, 9.99; N, 6.44.

$\mathrm{N}$-(2-Chloroethyl)- $\mathrm{N}$-ethyl- $\mathrm{N}$-isopropylpropan-1-aminium (6v). Yield: $75 \%$, mp: $200-202{ }^{\circ} \mathrm{C}$ dec., IR: 2974; 2879; 1464; 1411; 1129; 748. MS (ESI, $m / z): 192.2$. 1H NMR (300 MHz, DMSO- $\left.d_{6}\right): \delta 0.90(\mathrm{t}, 3 \mathrm{H}, J=7.2) ; 1.24(\mathrm{t}, 3 \mathrm{H}, J=7.5) ; 1.33$ (d, 6H, $\left.J=6.6\right) ; 1.66(\mathrm{hx}, 2 \mathrm{H}, J=$ 7.2); 3.26-3.33 (m, 2H); 3.44-3.51 (m, 2H); 3.65 (t, $2 \mathrm{H}, J=7.1$ ); 3.82 (septet, $1 \mathrm{H}, J=6.6$ ); 4.09 (t, $2 \mathrm{H}, J=7.1)$. 13C NMR (75 MHz, DMSO- $\left.d_{6}\right): \delta 8.8 ; 10.6 ; 16.2 ; 16.5 ; 36.7 ; 53.1 ; 56.7 ; 58.4$; 63.6. $\mathrm{C}_{10} \mathrm{H}_{23} \mathrm{Cl}_{2} \mathrm{~N}$ (228.2) calculated: $\mathrm{C}, 52.63 ; \mathrm{H}, 10.16 ; \mathrm{N}, 6.14$; found: $\mathrm{C}, 52.52 ; \mathrm{H}, 10.11 ; \mathrm{N}$, 6.25 .

$N$-(2-Chloroethyl)- $N$-isopropyl- $N$-methylpropan-2-aminium (6w). Yield: 84 \%, mp: 192-194 ${ }^{\circ} \mathrm{C}$ dec., IR: 2990; 2906; 1481; 1402; 1147; 729. MS (ESI, $\left.m / z\right)$ : 178.1. 1H NMR (300 MHz, DMSO- $\left.d_{6}\right): \delta 1.32-1.35(\mathrm{~m}, 12 \mathrm{H}) ; 2.93(\mathrm{~s}, 3 \mathrm{H}) ; 3.57$ (t, $\left.2 \mathrm{H}, J=7.1\right) ; 3.96$ (septet, $2 \mathrm{H}, J=6.6$ ); $4.10(\mathrm{t}, 2 \mathrm{H}, J=7.1)$. 13C NMR (75 MHz, DMSO- $\left.d_{6}\right): \delta 16.7$ (d); 37.1; 41.7; $56.0 ; 63.6$ $\mathrm{C}_{9} \mathrm{H}_{21} \mathrm{Cl}_{2} \mathrm{~N}$ (214.2) calculated: C, 50.47; H, 9.88; N, 6.54; found: C, 50.39; H, 9.84; N, 6.50 . $\mathrm{N}$-(2-Chloroethyl)- $\mathrm{N}$-ethyl- $\mathrm{N}$-isopropylpropan-2-aminium (6z). Yield: $79 \%$, mp: $188-190^{\circ} \mathrm{C}$ dec., IR: 2978; 2896; 1466; 1408; 1113; 766. MS (ESI, $m / z)$ : 192.2. 1H NMR (300 MHz, DMSO- $\left.d_{6}\right): \delta 1.27$ (t, 3H, $J=7.5$ ); 1.38 (d, 12H, $\left.J=6.6\right) ; 3.48$ (q, 2H, $\left.J=7.5\right) ; 3.63$ (t, $2 \mathrm{H}, J=$ 7.1); 3.99 (septet, $2 \mathrm{H}, J=6.6$ ); 4.09 (t, $2 \mathrm{H}, J=7.1$ ). 13C NMR (75 MHz, DMSO- $d_{6}$ ): $\delta$ 9.1; $16.5 ; 37.1 ; 53.1 ; 56.6 ; 63.5 . \mathrm{C}_{10} \mathrm{H}_{23} \mathrm{Cl}_{2} \mathrm{~N}(228.2)$ calculated: $\mathrm{C}, 52.63 ; \mathrm{H}, 10.16 ; \mathrm{N}, 6.14$; found: C, $52.563 ; \mathrm{H}, 10.27 ; \mathrm{N}, 6.10$. 


\section{Acknowledgements}

The authors gratefully acknowledge financial support by The Organization for the Prohibition of Chemical Weapons, The Hague, The Netherlands (No. L/ICA/ICB/84366/04), The State Office for Nuclear Safety, Czech Republic, and the Ministry of Education, Youth and Sports, Czech Republic (MSM6198959216). Authors would like to thank Dr. H. Koshino (RIKEN, Wako, Japan) for valuable discussions on NMR spectra of 1,1,4,4-tetrapropylpiperazinium diiodide.

\section{References}

1. The Convention on the Prohibition of the Development, Production, Stockpiling and Use of Chemical Weapons and on their Destruction, Organization for the Prohibition of Chemical Weapons (OPCW), The Hague 1994 (www.opcw.org).

2. Stýskala, J.; Cankar̆, P.; Soural, M.; Bednář, P.; Lemr, K. J. Label Compd. Radiopharm. 2008, 51, 19.

3. Papoušková, B.; Bednář, P.; Barták, P.; Fryčák, P.; Ševč́́k, J.; Stránský, Z.; Lemr, K. J. Sep. Sci. 2006, 29, 1531.

4. Papoušková, B.; Bednář, P.; Fryšová, I.; Stýskala, J.; Hlaváč, J.; Barták, P.; Ulrichová, J.; Jirkovský, J; Lemr, K. J. Mass Spectrom. 2007, 42, 1550.

5. Sterling, G. H.; Doukas, P. H.; Ricciardi, Jr., F. J.; Biedrzycka, D. W.; O’Neill, J. J. J. Neurochem. 1986, 46, 1170.

6. Tammelin, L. E. Acta Chem. Scand. 1957, 11, 859.

7. Tammelin, L. E. Ark. Kemi 1958, 12, 287.

8. Fredriksson, T. Arch. Int. Pharmacodyn. 1957, 113, 101.

9. Fredriksson, T. Arch. Int. Pharmacodyn. 1958, 115, 474.

10. Halámek, E.; Kobliha, Z. Collect. Czech Chem. Commun. 1992, 57, 56.

11. Burton, M. D.; Nouri, M.; Kazemi H. Brain Res. 1995, 670, 39.

12. Buccafusco, J. J. ; Aronstam, R. S. Neuropharmacol. 1988, 27, 227.

13. Stýskala, J.; Cankař, P.; Soural, M.; Bednáŕ, P.; Lemr, K. ARKIVOC 2007, (xv), 171.

14. Bednář, P.; Lemr, K.; Barták, P.; Ševč́́k, J.; Hlaváč, J.; Stýskala, J.; Wiedermannová, I.; Stránský, Z. J. Mass Spectrom. 2002, 37, 1213.

15. (a) Stýskala, J.; Cankař, P.; Soural, M; Bednář, P.; Lemr, K. ARKIVOC 2007, (xv), 171. (b) Parkkari, J. H.; Bannard, R. A. B.; Coleman, I. W. Can. J. Chem. 1965, 43, 3119. (c) Wright, J. B.; Lincoln, E. H.; Heinzelmann, R. V.; Hunter, J. H. J. Am. Chem. Soc. 1950, 72 , 3536.

16. Hanhart, W.; Ingold, C. K. J. Chem. Soc. 1927, 997.

17. Davidson, A. J.; George E. F. DE 1,925,073, 1969.

18. Gough, G. A. C.; King, H. J. Chem. Soc. 1928, 2426.

19. Leonard, L. J.; Paukstelis, J. V. J. Org. Chem. 1965, 30, 821. 
20. Gilsing, H. D.; Prescher, D.; Menz, D. H. Z. Anorg. Allg. Chem. 2007, 633, 1676.

21. Breitmaier, E.; Voelter, W. Carbon-13 NMR Spectroscopy; 3rd Ed., VCH: Weinheim, 1989.

22. Wu, X.; Toppet, S.; Compernolle, F.; Hoornaert, G. J. Tetrahedron 2003, 59, 1483.

23. Murray, R. W.; Kaplan, M. L. Tetrahedron 1969, 25, 1651.

24. Iriepa, I.; Madrid, A. I.; Gálvez, E.; Bellanato, J. J. Mol. Struct. 2006, 787, 8.

25. Raatikainen, K.; Huuskonen, J.; Kolehmainen, E.; Rissanen, K. Chem. Eur. J. 2008, 14, 3297.

26. (a) Hodgson, E.; Dauterman, W. C. J. Insect Physiol. 1964, 10, 1005. (b) Takeshige, Chifuyu; Pappano, Achilles J.; DeGroat, William C.; Volle, Robert L. Journal of Pharmacology and Experimental Therapeutics 1963, 141, 333.

27. Robinson, R. A. J. Org. Chem. 1951, 16, 1911.

28. Bannard, R. A. B.; Parkkari, J. H.; Coleman, I. W. Can. J. Chem. 1963, 41, 2108.

29. Koenig, K. H.; Pommer, H. US 3,557,214, 1971. 